\title{
Breast reshaping in gynecomastia by the "pull-through technique": considerations after 15 years
}

\author{
Paolo Giovanni Morselli • Andrea Morellini
}

Received: 27 January 2011 / Accepted: 11 May 2011 / Published online: 23 June 2011

(C) The Author(s) 2011. This article is published with open access at Springerlink.com

\begin{abstract}
Gynecomastia corresponds to abnormal and excessive development of breast tissue in male patients. It may be unilateral or bilateral and, depending on breast volume and skin redundancy, it can be classified, according to Simon, in four different groups. Standard therapy is surgery and different techniques have been described so far, including different type of incisions in the periareolar or intrareolar skin. In 1996 in this journal we described our personal technique, called "pull-through." Our technique combines liposuction that is performed on two planes, subcutaneous and subglandular, and sharp parenchymal excision, performed through the small liposuction incisions. These incisions are short $(1-1.5 \mathrm{~cm})$ and hidden in the inframammary fold and behind the anterior axillary pillar. Furthermore the operation can be performed under local anesthesia and with a short recovery period. Since then we have operated on 260 patients. We now present our 15 years experience and our review of literature, focused on authors who used and criticized our technique. Results, in terms of breast volume reduction, skin retraction, and minimal visibility of scars, were very good, even in cases more severe than in our first series (Simon's type IIb and femaleto-male transsexuals). Patients' satisfaction rate was high as well and the incidence of complications was low. The results we observed in our series and the ones presented by different authors confirmed the validity and feasibility of the "pull-through" technique in terms of esthetic and functional results, patient satisfaction, and a low incidence of complications.
\end{abstract}

P. G. Morselli • A. Morellini $(\bowtie)$

School of Plastic Surgery, University of Bologna,

Bologna, Italy

e-mail: andrea@morellini.info
Keywords Gynecomastia · Plastic surgery - Liposuction · Minimal scars

\section{Introduction}

Gynecomastia is the excessive breast enlargement in males, mimicking that of females. The term derives from two Greek words, $\gamma v \nu \varepsilon$ (female) and $\mu \alpha \sigma \tau$ os (breast). The incidence, as reported by different authors, ranges from $32 \%$ to $36 \%$ among adult males and even as high as $60 \%$ in adolescent boys. According to the etiology, gynecomastia can be classified as physiological, pathological, pharmacological, and idiopathic, the latter being the most common.

Three histological patterns have been identified, depending on different degrees of stromal and ductal proliferation: the florid pattern, the fibrous pattern, and the intermediate one. The three types represent the stages of evolution of the pathology: in the majority of cases, after a duration greater than 1 year, hypertrophic breast tissue becomes irreversibly fibrotic. For this reason medical treatment usually has limited success.

Depending on morphology and volume, gynecomastia is classified according to Simon (1973) in four different groups [1]:

I-Minor breast enlargement without skin redundancy, IIa-Moderate breast enlargement without skin redundancy,

$\mathrm{IIb}$-Moderate breast enlargement with minor skin redundancy, and

III-Gross breast enlargement with skin redundancy that mimics female breast ptosis.

Simon's classification offers a simple guideline for diagnosis and management: the different amount of adipose 
tissue, parenchyma, and skin redundancy are paramount in selecting patients and different surgical strategies. Actually, surgical correction is the accepted standard of treatment.

Many different techniques have been described and proposed and fall into three main groups:

- Excisional techniques adopting different approaches and incisions,

- Suction-assisted lipectomy, and

- Ultrasound-assisted liposuction.

In our opinion, the main issue is to achieve a pleasant chest wall shape, limiting scar extension, especially in the areolar area. The technique, first described in 1996 and called the pull-through technique, combines liposuction and parenchymal excision. Ten years after its publication, we reviewed our series, to obtain an accurate assessment based on a larger patient population and a longer follow-up.

\section{Surgery procedure}

The surgical procedure is always performed under general anesthesia. Markings are done with the patient in an upright position and include:

- Inframammary fold,

- Boundaries of liposuction, and

- Skin incisions, 8-12 $\mathrm{mm}$ long and set one behind the anterior axillary pillar and the other at the lateral extremity of the inframammary fold, due to the need for crossing liposuction tunnels and reaching the glandular tissue in the periareolar area.

A hypotonic solution and local anesthetic with epinephrine 1:400,000 is used for subcutaneous infiltration. This step is now performed in a different way than before: the solution is injected through the two skin incisions using a 2-mm multi-hole smooth cannula.

Twenty minutes after the solution has been injected, liposuction is performed. This is a wide and accurate liposuction with different aims:

- Fat tissue removal,

- Breast contour remodeling, and

- Glandular tissue isolation.

Fat tissue removal and contour reshaping are performed routinely in liposuction of the pectoral region. Isolation of the glandular tissue, however, is a specific step of this technique: the aim is to separate glandular tissue from its cutaneous and fascial attachments, in order to facilitate its following extraction in small pieces through the short skin incisions. In order to achieve that, liposuction is performed in a very meticulous way along two different planes; on the deeper one, a 4-mm preformatted "fingertip" [2] cannula is used above the pectoral fascia with the purpose of mobilizing glandular tissue. Treating the superficial plane, we use a thinner cannula $(2-3 \mathrm{~mm})$ to separate the parenchyma from the subcutaneous tissue, freeing the superficial layer skin attachments (Fig. 1).

The two layers must be meticulously created keeping in mind that the goal of the procedure is to detach glandular tissue almost completely both from the inferior plane and the superficial one. Once the parenchyma has been freed from its lower and superficial attachments, it can be mobilized: at this point of the procedure, the parenchyma mimics an octopus with its head corresponding to the areola. At the end of liposuction, the residual glandular tissue, located mostly in the subareolar area, can be pinched in order to localize and evaluate its shape and amount. The parenchyma to be excised is pinched between the thumb and the index, then it is clamped using a surgical forceps passed through the skin incisions (Fig. 2).

The instrument is then pulled out through the skin incision used for liposuction, the glandular tissue is exposed, and the parenchyma is excised using a scalpel or the electrocautery (Fig. 3). The piecemeal resection requires accurate inspection and palpatory check in order to minimize bleeding and avoid excessive removal with consequent skin irregularities. All the pieces of removed mammary tissue are collected and sent, as separated specimens from the right and left breast, for histological examination.

After glandular tissue removal has been completed, consistency and uniformity of the mammary area are checked by pinching the skin: additional liposuction, using a thin cannula can eventually be performed to smooth out contour irregularities, especially at the margins of the pectoral area and along the anterior axillary pillar. A suction drain is inserted on each side and maintained for 24-48 h. Skin incisions are sutured in layers, and stitches are removed on the eighth postoperative day. A compressive dressing is applied at the end of surgery and removed at the time of stitches' removal; after that, an elastic garment has to be worn until the end of the first postoperative month.

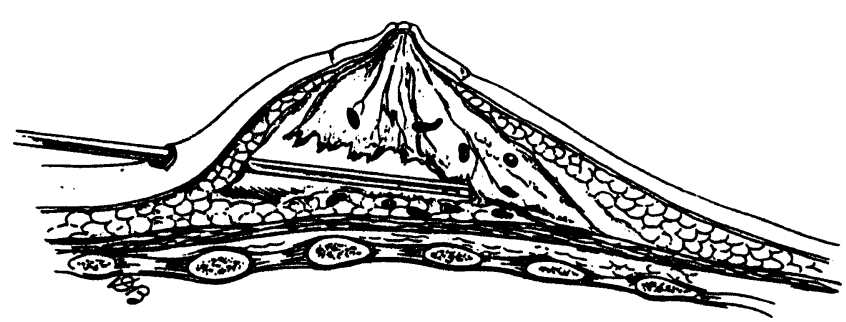

Fig. 1 The parenchyma is separated from the pectoral fascia using a liposuction cannula 
Fig. 2 The mammary parenchyma is clamped using a forceps and pulled out through the small liposuction incision

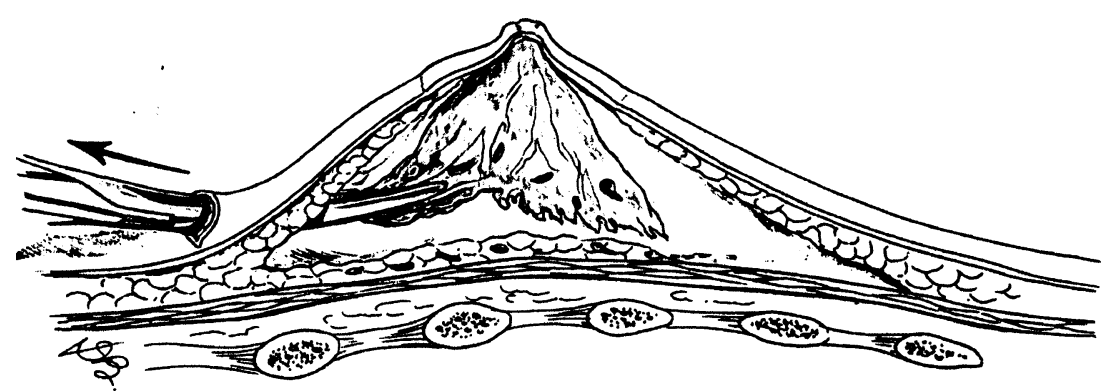

\section{Materials and methods}

Our series includes 260 patients, and the follow-up ranges from 1 to 15 years. Patients' age ranged from 10 to 59 years, but most of the cases included were between 18 and 30 years of age. The great majority of the cases $(92 \%)$ were bilateral with a small percentage of unilaterals. Since 2000 the technique was also applied in gender-confirming surgery to masculinize the chest wall in female-to-male transsexuals.

These specific patients were selected according to breast volume and ptosis: in cases of small or mediumsized breasts with mild or no ptosis [type I, IIa (Fig. 4a, b), and IIb (Fig. 5a, b) according to Simon's classification], the "pull-through" technique was applied. Sixty patients underwent chest wall remodeling using this procedure: they all underwent hysterectomy and ovarectomy at the same sitting.

Patients operated so far can be divided as follows (Figs. 6a, $\mathrm{b}$ and $7 \mathrm{a}, \mathrm{b}$ ):

- Simon's type I, 17\%;

- Simon's type IIa, 45\%;

- Simon's type IIb, 30\%; and

- Unilateral cases, $8 \%$.

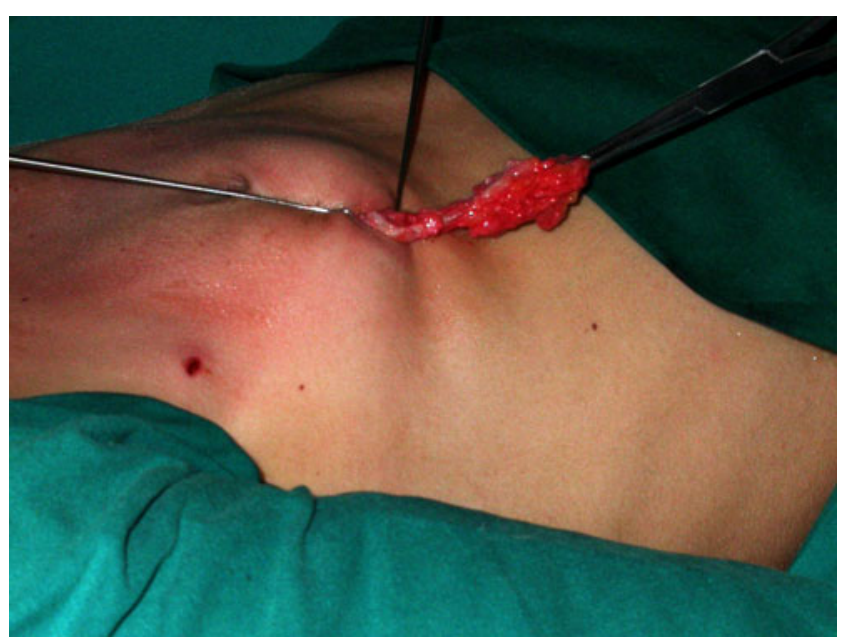

Fig. 3 Intraoperative picture showing the glandular tissue pulled through the incision in the inframammary fold
All surgery was performed under general anesthesia: $20 \%$ of the patients underwent the operation as a 1-daysurgery regimen, while the remaining $80 \%$ were hospitalized for a period of $24 \mathrm{~h}$. In all the cases, suction drains were applied and, according to the amount of bleeding, withdrawn after $24-48 \mathrm{~h}$. The stitches were removed on the eighth postoperative day. All the patients had to wear a compressive elastic dressing for at least 1 month after surgery and limit their physical activities for another one. Controls were planned at 8,15 , and 30 days after surgery, then at 2, 6, and 12 months. The longest follow-up was 15 years (eight patients).

\section{Results}

\section{Volume}

In all the cases, a significant reduction of breast volume with glandular tissue removal was achieved and skin retraction led to a good male-looking chest. In the latter series, large amounts of volume, even $300 \mathrm{ml}$ of parenchyma, had been resected using this technique. The same results were recorded in the group of female patients undergoing gender-confirming surgery. Further tailoring was necessary only in $4 \%$ of cases, mainly during our earlier experience and it was due to insufficient gland tissue removal: in these patients, the remaining parenchyma was more evident in the subareolar area and additional pull-through excision had to be performed under local anesthesia.

Function and sensitivity

All the patients were satisfied with the result, and none had functional impairment of the arms. Only $20 \%$ of them were referred for transient reduction of the nipple-areola complex sensitivity and complete recovery was achieved in 2-8 months.

Scars

Wound healing was completed in 8-10 days, and scars were almost undetectable in the majority of cases. 
a
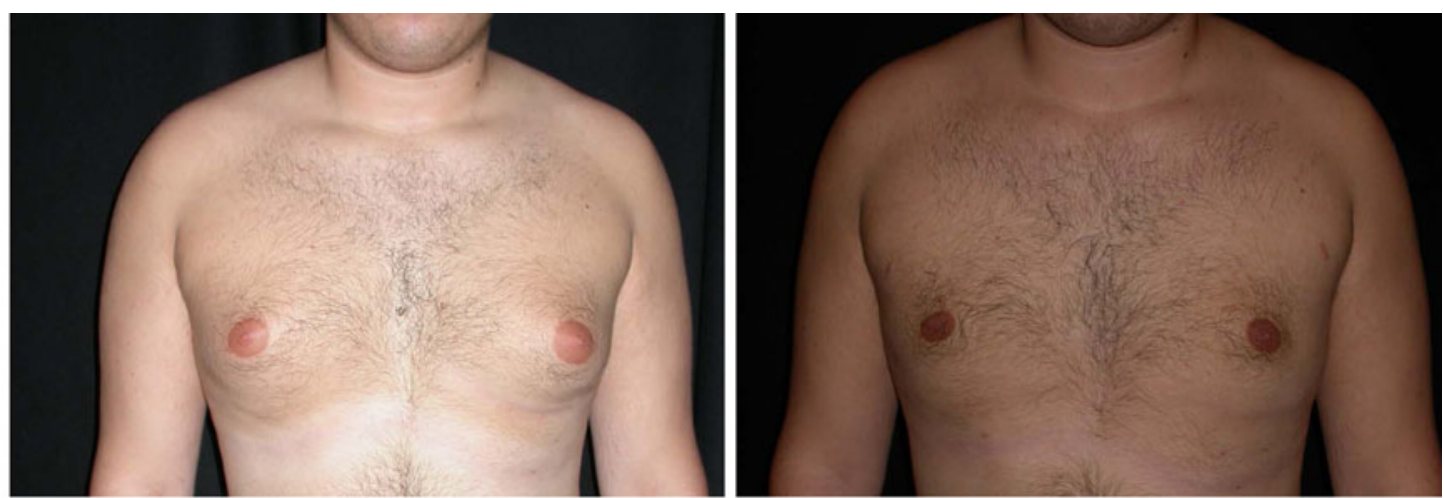

b
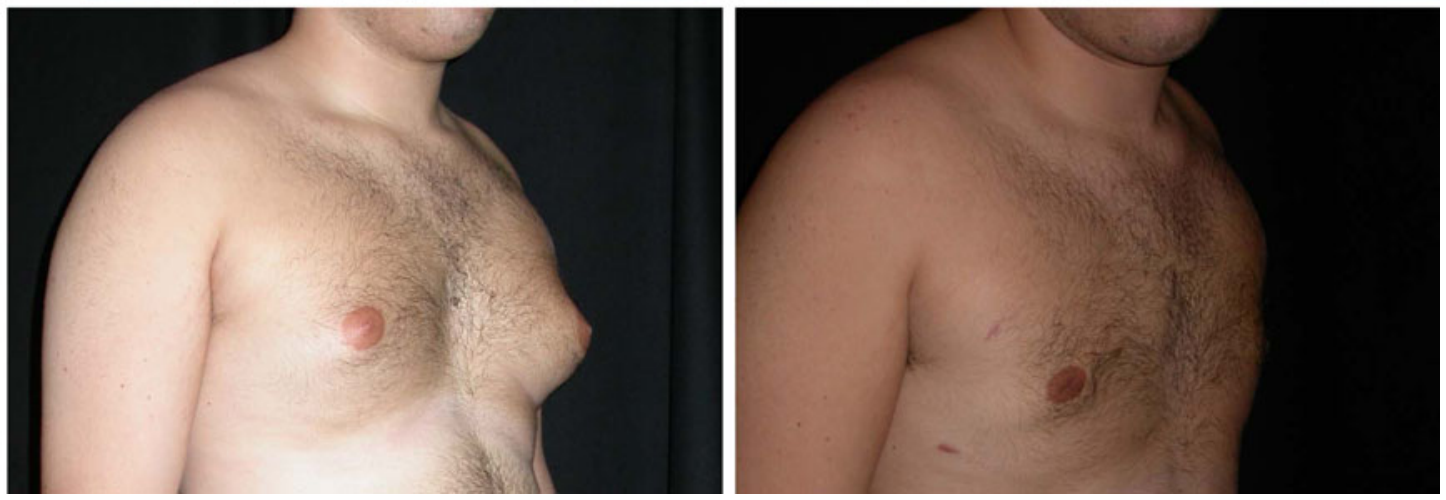

Fig. 4 a, b Preop and postop pictures of adult male patient classified as Simon type IIa
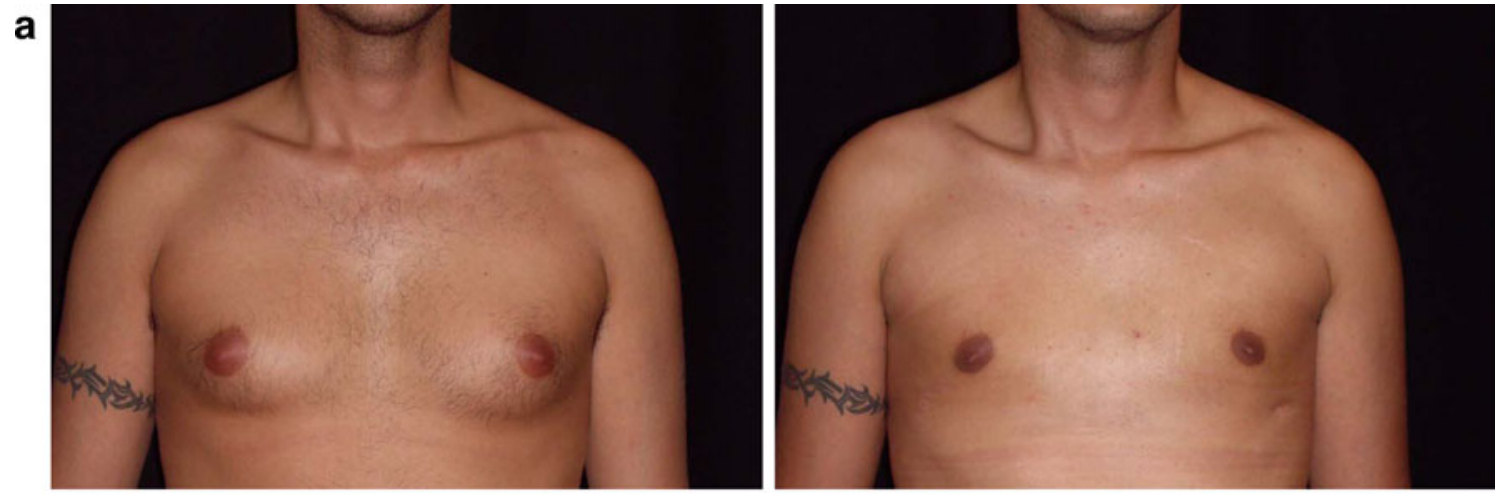

b
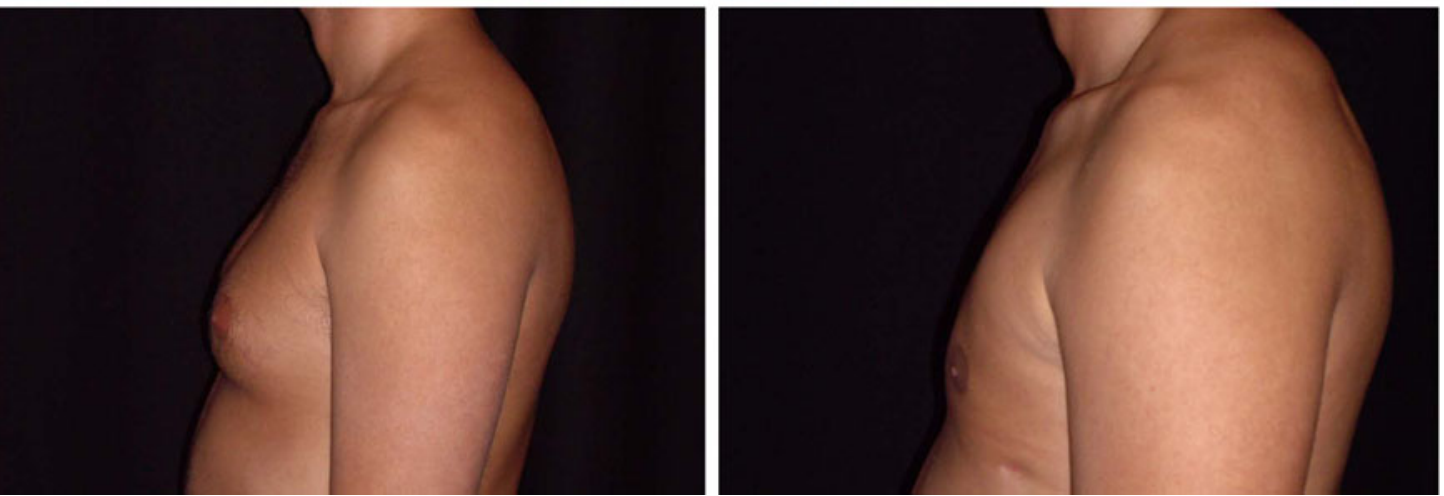

Fig. 5 a, b Preop and postop pictures of adult male patient classified as Simon type IIb 
a
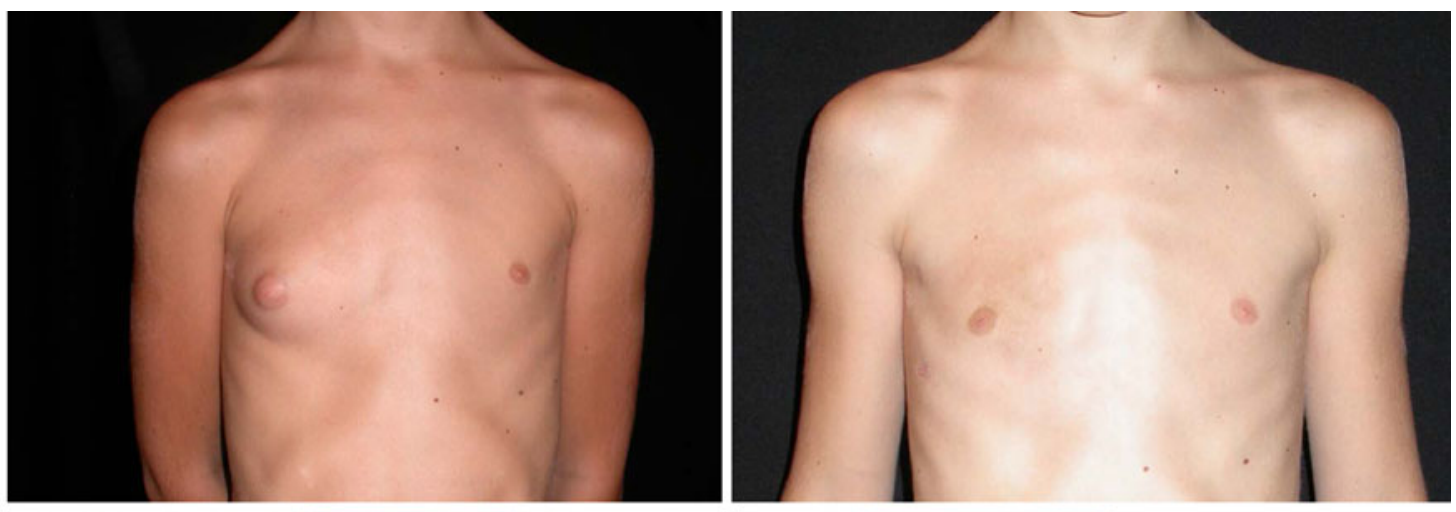

b
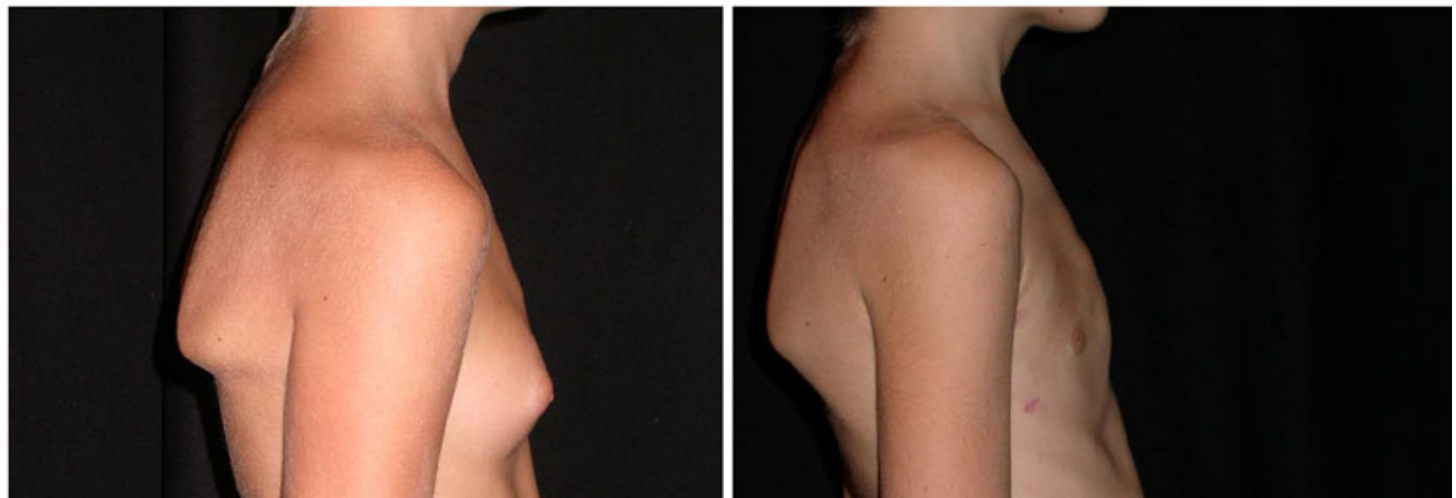

Fig. 6 a, b Preop and postop pictures of child male patient, presenting unilateral gynecomastia classified as Simon type I

a

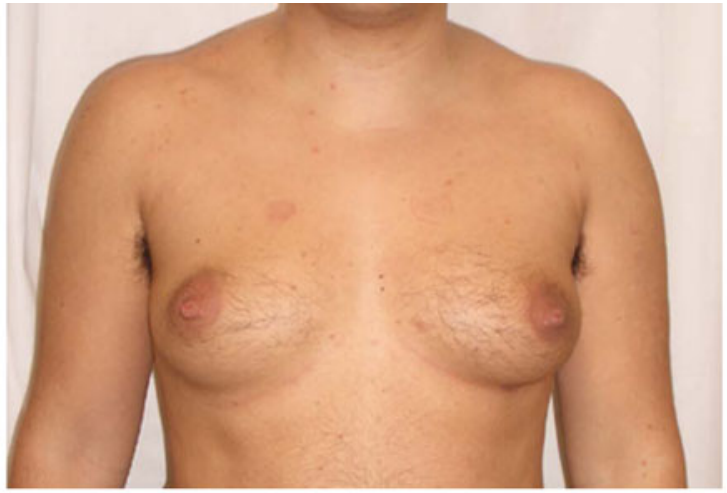

b

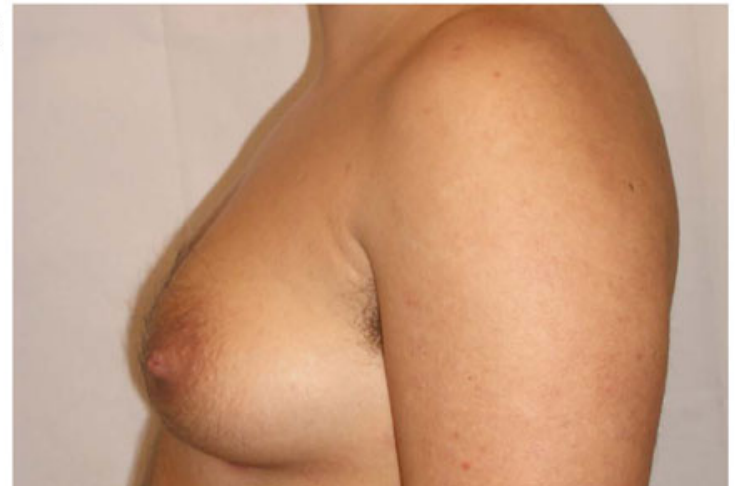

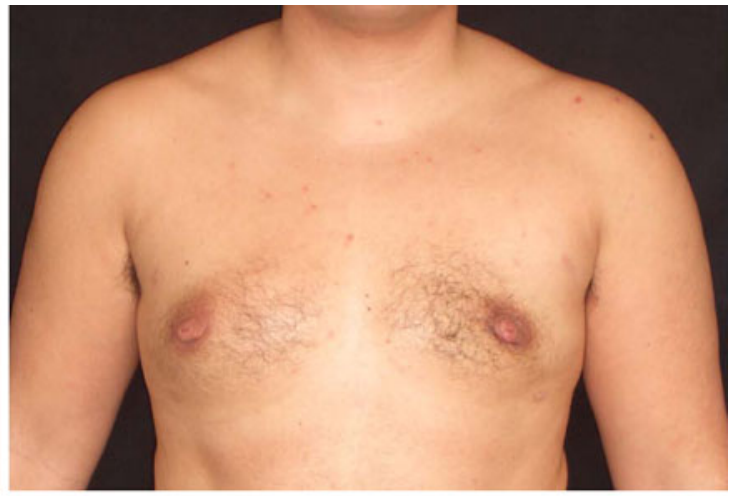

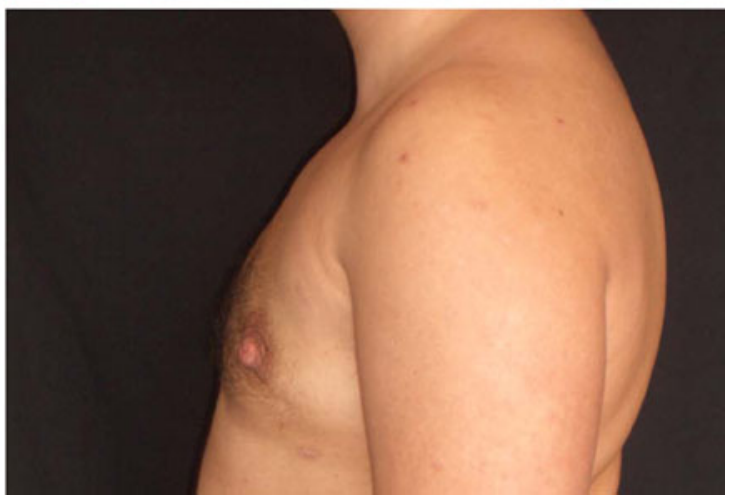

Fig. 7 a, b Preop and postop pictures of adult transsexual female patient classified as Simon type III 
Hypertrophy and/or hyperpigmentation of the inframammary scar were recorded in $2 \%$ of cases while wide scars were present in $3 \%$. In these cases scar revision was performed 1 year after the operation.

\section{Skin irregularities}

Excessive gland removal or excessive liposuction can lead to irregularities of the skin surface. This undesirable event is very obnoxious for the patient and sometimes very difficult to correct. In our series only $4 \%$ of the patients had irregularities of the skin surface in the mammary area, most among the early cases and they were due to excessively aggressive gland resection and/or liposuction. Skin irregularities were corrected by further superficial liposuction and or lipofilling performed under local anesthesia.

\section{NAC deformities}

In $1 \%$ of patients, nipple-areola complex impairment occurred: half of them showed areola skin retraction with areolar deformities, while the other half had complications due to desepithelization of the areola followed by scar formation. These complications, both due to excessive superficial liposuction or undermining, occurred in the earlier series and were corrected by fat injection and scar revision.

\section{Infections}

No surgical infections were ever reported in our series.

\section{Bleeding}

In $2 \%$ of our patients, excessive postoperative bleeding occurred and in $1 \%$ of the cases, subcutaneous hematomas were drained.

\section{Discussion}

Many different techniques have been proposed and described to remove breast tissue in male patients with gynecomastia. The choice should be guided by the severity of the deformity in terms of breast volume and skin redundancy. The ideal procedure should masculinize chest contours while respecting the areolar complex and minimizing surgical trauma. Albeit malignancy and breast cancer in male patients reported only in $0.5 \%$ of the cases, Mladick [3] and other authors stress the importance of resecting the parenchyma instead of suctioning it in order to have specimens for the pathologist.
Compared to surgical procedures that use a periareolar approach [4], the technique we employ offers many important advantages, both esthetic and functional:

- No incisions in the areolar complex are necessary, avoiding risk of retraction, distortion, and sensory impairment; as described for other techniques based on liposuction. Areolar deformities are only possible as consequence of excessive tissue removal just below the areola.

- Skin incisions are small $(8-10 \mathrm{~mm})$ and placed at the inframammary fold and behind the anterior axillary pillar, that is at the margin and away from the pectoral esthetic unit, following one of the pillars of plastic surgery.

Compared to liposuction alone, as described by Rosenberg and Becker, we find our technique more effective and safer:

- Direct visualization of the parenchyma is possible, this allows a more extensive and radical removal of breast tissue with no or minimal risk of relapses.

- Direct control of bleeding and hemostasis reduces the incidence of postoperative hematoma.

- The pull-through technique combines the advantages of suctioning procedures with preservation and availability of breast tissue to be examined.

Some authors have proposed technical variations. Bracaglia and others [5] described their pull-through experience using only three incisions (one at the level of each anterior axillary line and a median one at the level of the sternal midline). Lista and Ahmad [6] referred to the use of our technique in association with power-assisted liposuction (PAL) while Ramon and others [7] associated the PAL technique with endoscopic-assisted pull-through excision.

We found the technique to be straightforward and followed the procedure as it was first described: we never felt the need for the aid of an endoscope since direct exposure of the parenchyma by pulling it out allows complete control of the excision and hemostasis. Regarding the PAL, this could offer the chance to reduce surgical time and fatigue, nevertheless we feel that traditional liposuction allows more sensitive control of the cutaneous flap thickness, especially in the more delicate regions (below the NAC and along the borders of the pectoral area).

What are the limits and disadvantages of the pullthrough technique? Certainly, at the beginning, the procedure is more time-consuming compared with liposuction alone or with techniques utilizing a wider access. Furthermore a learning curve is necessary although this is not as long as it might seem. The main issue is to achieve good sensitivity in parenchymal resection, avoiding unpleasant 
NAC deformities and to check hemostasis: in fact, in earlier cases, the hematoma rate was higher. A good way to prevent hematoma is to resect a small amount of parenchyma and to carefully verify hemostasis after each piecemeal resection.

After 15 years of experience, we can confirm that we are satisfied with this surgical technique: during this period of the good results, we extended indications to include patients undergoing gender-confirming surgery. Furthermore, a review of the literature showed how the pull-through technique has been well accepted and adopted by other surgeons with favorable results. The main point, in our opinion, is that the technique combines simplicity and effectiveness while minimizing and concealing surgical scars.

Open Access This article is distributed under the terms of the Creative Commons Attribution Noncommercial License which permits any noncommercial use, distribution, and reproduction in any medium, provided the original author(s) and source are credited.

\section{References}

1. Simon B, Hoffman S, Kahn S (1973) Classification and surgical correction of gynecomastia. Plast Reconstr Surg 51 (1):48-52

2. Morselli PG (2000) Temporalis muscle hypertrophy: a new plastic surgery procedure. Plast Reconstr Surg 106:1156-1161

3. Mladick RA (1991) Gynecomastia: liposuction and excision. Clin Plast Surg 18:815

4. Rohrich RJ, Ha RY, Kenkel JM, Adams WP (2003) Classification and management of gynecomastia: defining the role of ultrasoundassisted liposuction. Plast Reconstr Surg 111(2):909-923

5. Persichetti P, Berloco M, Muccioli Casadei R, Marangi G, Di Lella F, Nobili A (2001) Gynecomastia and the complete circumareolar approach in the surgical management of skin redundancy. Plast Reconstr Surg 107(4):948-954
6. Lista F, Ahmad J (2008) Power-assisted liposuction and the pullthrough technique for the treatment of gynecomastia. Plast Reconstr Surg 121(3):740-747

7. Ramon Y, Fodor L, Peled IJ, Eldor L, Egozi D, Ullmann Y (2005) Multimodality gynecomastia repair by cross-chest power-assisted superficial liposuction combined with endoscopic-assisted pullthrough excision. Ann Plast Surg 55(6):591-594

\section{Further reading}

Morselli PG (1996) "Pull-through": a new technique for breast reduction in gynecomastia. Plast Reconstr Surg 97:450-454

Letterman G, Schurter M (1972) Surgical correction of massive gynecomastia. Plast Reconstr Surg 28:177

Dufourmentel L (1928) L'incision areolaire dans la chirurgie du sein. Bull Mem Soc Chir Paris 20:9

Webster JP (1990) Mastectomy for gynecomastia through a semicircular intra-areolar incision. Ann Surg 12:557

Pitanguy I (1966) Transareolar incision for gynecomastia. Plast Reconstr Surg 38:414

Letterman G, Schurter M (1969) Surgical correction of gynecomastia. Am Surg 35:322

Huang TT, Hidalgo JE, Lewis SR (1982) A circumareolar approach in surgical management of gynecomastia. Plast Reconstr Surg 69:35

Rosenberg GJ (1987) Gynecomastia: suction lipectomy as a contemporary solution. Plast Reconstr Surg 80:379

Becker H (1990) The treatment of gynecomastia without sharp excision. Ann Plast Surg 24:380

Courtiss HE (1987) Gynecomastia: analysis of 159 patients and current recommendations for treatment. Plast Reconstr Surg 79:740-750

Davidson BA (1979) Concentric circle operation for massive gynecomastia to excise the redundant skin. Plast Reconstr Surg 63(3):350-354

Balch CR (1978) A transaxillary incision for gynecomastia. Plast Reconstr Surg 61(1):13-16

Bracaglia R, Fortunato R, Gentileschi S, Seccia A, Farallo E (2004) Our experience with the so-called pull-through technique combined with liposuction for management of gynecomastia. Ann Plast Surg 53(1):22-26 